\title{
Detection of Melamine Based on the Fluorescence Changes of Nitrogen-Doped Carbon Dots
}

\author{
Wenzhi Yin, ${ }^{1,2,3}$ Chaoqun Ma, ${ }^{1,3}$ Tuo Zhu, ${ }^{1,3}$ Jiao Gu, ${ }^{1,3}$ Chun Zhu, ${ }^{1,3}$ Lei Li, ${ }^{1,3}$ \\ and Guoqing Chen $\mathbb{1}^{1,3}$ \\ ${ }^{1}$ School of Science, Jiangnan University, Wuxi 214122, China \\ ${ }^{2}$ School of Internet of Things Engineering, Jiangnan University, Wuxi 214122, China \\ ${ }^{3}$ Jiangsu Provincial Research Center of Light Industrial Optoelectronic Engineering and Technology, Wuxi 214122, China
}

Correspondence should be addressed to Guoqing Chen; jncgq@jiangnan.edu.cn

Received 15 January 2021; Revised 31 March 2021; Accepted 16 April 2021; Published 24 April 2021

Academic Editor: Jau-Wern Chiou

Copyright (c) 2021 Wenzhi Yin et al. This is an open access article distributed under the Creative Commons Attribution License, which permits unrestricted use, distribution, and reproduction in any medium, provided the original work is properly cited.

In order to determine the concentration of melamine, nitrogen-doped carbon dots (NCDs) were synthesized in one step as a fluorescent probe. Uric acid and diethylenetriamine were used as carbon source and nitrogen source, respectively. The experimental results showed that the fluorescence of NCDs can be quenched by mercury ions $\left(\mathrm{Hg}^{2+}\right)$. Due to the strong coordination affinity between the carbon-nitrogen heterocyclic of melamine and $\mathrm{Hg}^{2+}$, part of $\mathrm{Hg}^{2+}$ coordinated with melamine when melamine was mixed with $\mathrm{Hg}^{2+}$. Then, the fluorescence of the added NCDs was quenched by the remaining $\mathrm{Hg}^{2+}$. Therefore, the concentration of melamine could be determined. The results show that the method has high sensitivity in wide measuring range that the linear ranges are $50-400 \mu \mathrm{g} / \mathrm{L}$ and $800-2500 \mu \mathrm{g} / \mathrm{L}$, and the $R^{2}$ is 0.997 and 0.988 , respectively, with the limit of detection (LOD) of $21.76 \mu \mathrm{g} / \mathrm{L}$. The NCDs are easy to fabricate, and the detection method is easy to implement. In this study, a new method for melamine detection was established, and the proposed method for melamine detection can provide some insights for food safety detection.

\section{Introduction}

Melamine $\left(\mathrm{C}_{3} \mathrm{H}_{6} \mathrm{~N}_{6}\right)$, an organic compound with triazine nitrogen-containing heterocycle, has been widely used in plastics and coating industry $[1,2]$. The main use of melamine was a raw material of melamine formaldehyde (MF) resin [3]. MF was used as paint, paper, and decorative panels because of its advantage of nonflammability, water resistance, heat resistance, and insulation. Unfortunately, melamine was adulterated into milk due to its high nitrogen contents $(66 \%)$ by some illegal vendors $[4,5]$. Long-term intake of melamine can cause kidney stones, obstructive renal failure, and even death, especially in infants $[6,7]$. In this context, the limit value of melamine in food was announced in China in 2011. The limit value of melamine in infant formula was $1 \mathrm{mg} / \mathrm{kg}$, and in other general foods, it was $2.5 \mathrm{mg} / \mathrm{kg}$, specifically [8]. Hence, it is necessary to develop a simple and feasible method to meet the requirements of melamine determination.

At present, there are a number of detection methods for melamine, such as enzyme-linked immune sorbent assay (ELISA) [9, 10], colloidal gold immune-chromatographic assays (GICA) [11], high performance liquid chromatography (HPLC) $[12,13]$, liquid chromatography-mass spectrometry (LC-MS) $[14,15]$, gas phase chromatography-mass spectrometry (GC-MS) [16, 17], electrospray ionizationmass spectrometry (ESI-MS) [18], and near-infrared (NIR) [19]. These methods have the advantages of high sensitivity and high accuracy. However, these methods may have the inherent drawbacks of complicated pretreatment steps and long operation time.

Fluorescence spectroscopy (FS) can reflect the characteristics of the target molecule. It can be used for qualitative or quantitative detection of the target molecule. Fluorescence spectroscopy has been applied to the precise detection 
of many complex mixture systems because it has the advantages of good selectivity, high sensitivity, simple operation, and small sample volume. Up to now, in order to improve the sensitivity of detecting the concentration of melamine, some nanomaterials had been used as fluorescent probes for the quantitative detection of melamine. The utilization of gold nanoparticles and CdTe quantum dots to detect melamine had been reported [20-24]. These probes had good sensitivity and selectivity. Meanwhile, they may have the problems of high toxicity for CdTe and high cost for gold nanoparticles. So, it is necessary to look for new probes to detect melamine.

Carbon dots were widely used in heavy metal ions, photocatalysis, LED, and sensing because of its simple synthesis, low cost, low toxicity, and high specificity $[25,26]$. In order to detect melamine, a fluorescence resonance energy transfer system between carbon dots and gold nanoparticles was established by Li [27]. Yang exploited a colorimetric sensor platform to detect melamine by using carbon dots and silver nanocomposite [28]. Zhu proposed a simpler and more cost-effective method to detect melamine which reduced the fluorescence quenching of carbon dots by $\mathrm{Hg}^{2+}$ through the combination of melamine and $\mathrm{Hg}^{2+}$ [29]. In order to obtain a more sensitive and rapid method for the detection of melamine, further investigation should be explored.

In this study, a method for indirectly detecting the concentration of melamine using the fluorescence intensity of the system was established. The prepared NCDs are used as fluorescent probes. By the mechanism of the strong coordination affinity between melamine and $\mathrm{Hg}^{2+}$, the fluorescence of NCDs can be quenched by $\mathrm{Hg}^{2+}$. The melamine$\mathrm{Hg}^{2+}$-NCDs system is established by researching the interaction between these three kinds of materials. The relationship between the fluorescence intensity of the system and the melamine concentration was studied. Additionally, the method has the advantages of simple operation, short detection time, and high sensitivity in comparison with the methods employing other fluorescent probes.

\section{Materials and Methods}

2.1. Reagents and Apparatus. Melamine, uric acid (UA), diethylenetriamine (DETA), $\mathrm{Hg}\left(\mathrm{NO}_{3}\right)_{2} \cdot \mathrm{H}_{2} \mathrm{O}$, urea, biuret, tryptophan (Trp), phenylalanine (Phe), tyrosine (Tyr), valine (Val), alanine (Ala), and glycine (Gly) were obtained from Sinopharm Chemical Reagent Co., Ltd. (Shanghai, China).

The fluorescence measurements were conducted using the FLS920P fluorescence spectrometer produced by Edinburg, England. Absorption spectra were collected on the Shimadzu UV2600 absorption spectrometer.

2.2. Synthesis of NCDs. The NCDs was prepared as previously reported papers [30]. Briefly, UA $(0.1 \mathrm{~g})$ was dissolved in DETA $(645 \mu \mathrm{L})$. The mixed solution was heated from room temperature to $170^{\circ} \mathrm{C}$ in oil bath. The temperature was kept at $170^{\circ} \mathrm{C}$ for $30 \mathrm{~min}$. Then, the reaction flask was cooled to room temperature after taken from the oil bath. After being washed by acetone, the precipitate was collected by centrifugation. After drying, NCDs were dissolved in deionized water to the absorbance of 0.15 at $350 \mathrm{~nm}$. Then, four kinds of concentrations of NCDs were obtained by diluting NCDs 5 times, 10 times, and 15 times, respectively. Finally, NCDs were stored in the dark at $4^{\circ} \mathrm{C}$ before further use.

2.3. Fluorescence Spectra and Absorption Spectra of $\mathrm{Hg}^{2+}$ NCDs. NCDs $(500 \mu \mathrm{L})$ were added to $100 \mu \mathrm{L}$ mercury nitrate $(1-8 \mathrm{mM})$. After maintaining the reaction at room temperature for $5 \mathrm{~min}$, the absorption spectrum and fluorescence emission spectrum $\left(\lambda_{\mathrm{ex}}=370 \mathrm{~nm}\right)$ were measured. The excitation and emission slit widths of the optical spectrometer were set to $2.5 \mathrm{~nm}$ and $1 \mathrm{~nm}$, respectively.

2.4. Fluorescence Spectra of Melamine- $\mathrm{Hg}^{2+}-\mathrm{NCDs}$. Aqueous solution of melamine with a concentration range of $0-10 \mathrm{mg} / \mathrm{L}$ was configured. $1.2 \mathrm{mM}$ mercury nitrate $(100 \mu \mathrm{L})$ was added to melamine solution $(3 \mathrm{~mL})$. After maintaining the reaction at room temperature for $5 \mathrm{~min}, 500 \mu \mathrm{L}$ NCDs (diluted 5 times) was added. After being shaken for $5 \mathrm{~min}$, mixed solution was obtained. Then, the fluorescence emission spectrum of mixed solution $\left(\lambda_{\mathrm{ex}}=370 \mathrm{~nm}\right)$ was measured. Excitation and emission slit width was set to $2 \mathrm{~nm}$ and $1 \mathrm{~nm}$, respectively.

\section{Results and Discussion}

3.1. Spectral Properties of NCDs. The absorption spectrum, fluorescence excitation spectrum, and emission spectrum of NCDs were measured, and the results are shown in Figure 1. There are two obvious absorption peaks at wavelengths of $279 \mathrm{~nm}$ and $350 \mathrm{~nm}$, which may be related to the $\pi-\pi^{*}$ transition of $\mathrm{sp}^{2}$ hybridization and the $\mathrm{n}-\pi^{*}$ broadened absorption bands of $C=O$ transitions, respectively [30]. When excited at $370 \mathrm{~nm}$, the NCDs show a strong fluorescence at $440 \mathrm{~nm}$. It can be observed in Figure 1 insets that the solution of NCDs is light yellow when exposed to sunlight and blue when exposed to $365 \mathrm{~nm}$ ultraviolet light.

3.2. Fluorescence Quenching of NCDs by $\mathrm{Hg}^{2+}$. The fluorescence emission spectra of the mixed solutions of NCDs and mercury nitrate with different concentrations were obtained under the excitation wavelength of $370 \mathrm{~nm}$ (Figure 2(a)). The inset is the graph of the fluorescence peak intensity changing with the concentration of $\mathrm{Hg}^{2+}$. It can be seen that the fluorescence intensity of NCDs decreases rapidly as the concentration of $\mathrm{Hg}^{2+}$ gradually increases. When the concentration of $\mathrm{Hg}^{2+}$ is $6 \mathrm{mM}$, the fluorescence intensity of NCDs is quenched by $93.6 \%$. It shows that there is a strong quenching relationship between $\mathrm{Hg}^{2+}$ and NCDs. However, as the concentration of $\mathrm{Hg}^{2+}$ continues to increase to $8 \mathrm{mM}$, the percentage of fluorescence quenching degree of NCDs is only increased from $93.6 \%$ to $96 \%$. The tendency of quenching fluorescence tends to be flat. In order to avoid excessive $\mathrm{Hg}^{2+}$ from affecting the sensitivity of melamine 


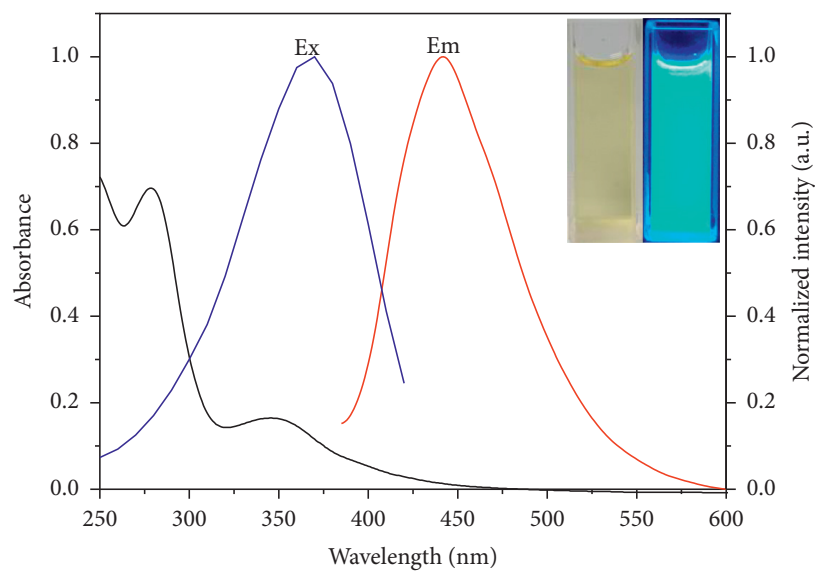

FIgURE 1: The absorption (black line), fluorescence excitation spectrum (blue line), and emission spectrum (red line) of NCDs. Insets show photographs of aqueous solution of NCDs with the exposure of visible (left) and ultraviolet (right) light $(365 \mathrm{~nm})$.

detection, the concentration of $\mathrm{Hg}^{2+}$ is selected as $6 \mathrm{mM}$. Experiments show that the fluorescence quenching degree of NCDs is close when the NCDs and $\mathrm{Hg}^{2+}$ are diluted in the same volume ratio. It was mentioned in the previous study that the quenching process was $1 \mathrm{~min}[30]$. In order to combine $\mathrm{Hg}^{2+}$ and NCDs more completely, the mixing time in the experiment was set as $5 \mathrm{~min}$.

The absorption spectra of mixed solutions with different concentrations of mercury nitrate and NCDs were measured (Figure 2(b)). It can be seen that the absorption peak of NCDs at $350 \mathrm{~nm}$ does not change significantly as $\mathrm{Hg}^{2+}$ is added into the solution system. The absorption spectrum is not changed, which indicates that the fluorescence quenching of NCDs is a dynamic quenching. Due to the interaction between the excited molecule and the quencher, the fluorescence is quenched. It suggests that there is a strong binding affinity and a faster chelation reaction between $\mathrm{Hg}^{2+}$ and the NCDs group. The electronic structure of NCDs is changed, and the distribution of excitons is affected. Then, with an effective electron transfer process, the nonradiative recombination of excitons is promoted [31, 32].

3.3. The Mechanism of the Melamine- $\mathrm{Hg}^{2+}-\mathrm{NCD}$ system for Detecting Melamine. The fluorescence emission spectra of NCDs, NCDs-melamine mixed solution, melamine- $\mathrm{Hg}^{2+}$ NCDs mixed solution, and NCDs- $\mathrm{Hg}^{2+}$ mixed solution were measured $\left(\lambda_{\mathrm{ex}}=370 \mathrm{~nm}\right)$ (Figure 3). It can be seen that the fluorescence of NCDs is quenched by $\mathrm{Hg}^{2+}$ in the black line. The fluorescence of NCDs is not significantly affected by melamine shown as the gray line. As shown as red line, melamine $(3 \mathrm{mg} / \mathrm{L})$ is mixed with $\mathrm{Hg}^{2+}$. Then, NCDs are added. At this time, the fluorescence of NCDs is only quenched by $18.6 \%$ since $\mathrm{Hg}^{2+}$ is partially bound by melamine.

The process of the melamine- $\mathrm{Hg}^{2+}{ }^{2} \mathrm{NCD}$ system is shown in Scheme 1 [29]. First, NCDs can produce strong fluorescence under the excitation of light $\left(\lambda_{\mathrm{ex}}=370 \mathrm{~nm}\right)$. Then, the fluorescence of NCDs can be quenched by $\mathrm{Hg}^{2+}$ on the first line of Scheme 1. When a mixed solution of melamine and $\mathrm{Hg}^{2+}$ is added to the NCDs, melamine is coordinated with part of $\mathrm{Hg}^{2+}$ due to the strong coordination affinity between melamine and $\mathrm{Hg}^{2+}$ on the second line of Scheme 1. The fluorescence of NCDs is quenched by the remaining $\mathrm{Hg}^{2+}$. Finally, the fluorescence intensity of NCDs has an obvious relationship with the concentration of melamine. The less $\mathrm{Hg}^{2+}$ is free because of the higher melamine concentration. The less fluorescence of NCDs is quenched by $\mathrm{Hg}^{2+}$, the higher fluorescence intensity of the system [21, 33]. Based on this mechanism, the indirect detection of melamine using NCDs and $\mathrm{Hg}^{2+}$ is realized.

3.4. The Optimization of the Mixing Sequence of Melamine, $\mathrm{Hg}^{2+}$, and NCDs. The order of addition of melamine, $\mathrm{Hg}^{2+}$, and NCDs had a greater impact on the experiment. The fluorescence emission spectra of NCDs- $\mathrm{Hg}^{2+}$ mixed solution, melamine- $\mathrm{Hg}^{2+}$-NCDs mixed solution, melamine$\mathrm{NCDs}-\mathrm{Hg}^{2+}$ mixed solution, and $\mathrm{NCDs}-\mathrm{Hg}^{2+}$-melamine mixed solution are shown in Figure $4\left(\lambda_{\mathrm{ex}}=370 \mathrm{~nm}\right)$.

It can be seen in Figure 4 that the fluorescence intensity of the system has a certain difference due to the different order of addition. The fluorescence intensity of the gray line is close to the black line. It indicates that NCDs and $\mathrm{Hg}^{2+}$ have a strong binding affinity and are relatively stable after being mixed. They will not be affected by the added melamine. The fluorescence intensity of the blue line is close to the black line too. It suggests that $\mathrm{Hg}^{2+}$ will be preferentially or quickly combined with NCDs after being added to the mixed solution of melamine and NCDs, which causes melamine to fail to coordinate with $\mathrm{Hg}^{2+}$. The fluorescence intensity of the red line is significantly higher than the black line. The fluorescence of NCDs is only partially quenched, since $\mathrm{Hg}^{2+}$ is first combined with melamine. Therefore, the order of addition selected in this study is melamine and $\mathrm{Hg}^{2+}$ are mixed first and then NCDs are added.

3.5. The Optimization of NCDs Concentration for the Determination of Melamine. The concentration of NCDs had a greater impact on the detection of melamine. Comparison of the fluorescence peak intensity (normalized) of the melamine- $\mathrm{Hg}^{2+}-\mathrm{NCD}$ system is shown in Figure 5. The 


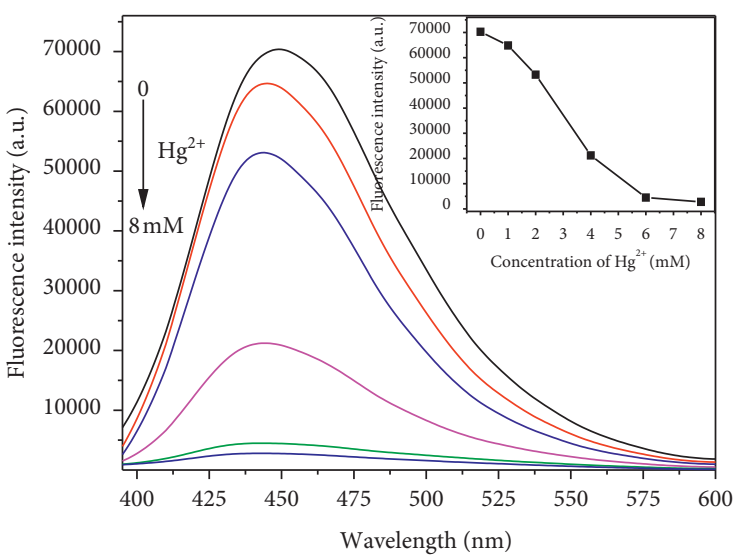

(a)

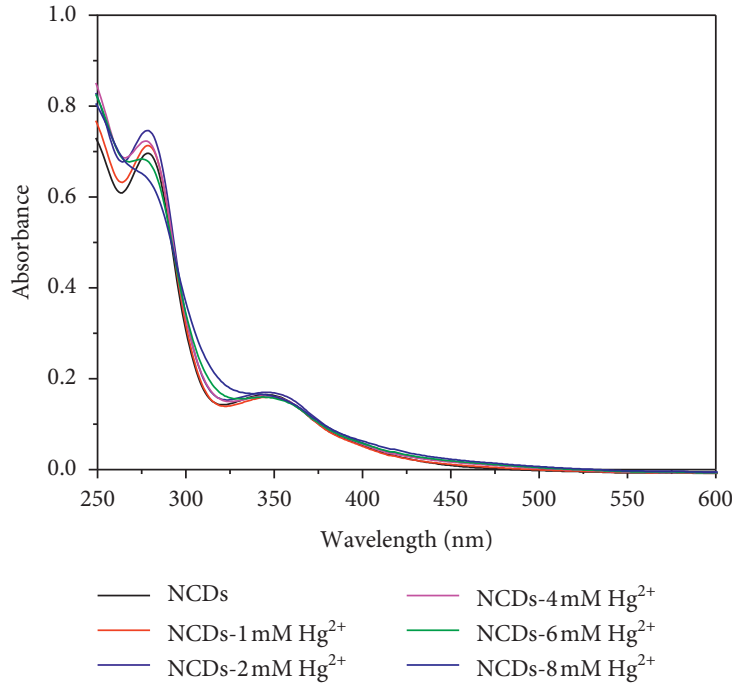

(b)

Figure 2: (a) The fluorescence emission spectra of the mixed solutions of mercury nitrate and NCDs with different concentrations $\left(\lambda_{\mathrm{ex}}=370 \mathrm{~nm}\right.$ ). Inset of (a) shows the graph of the fluorescence peak intensity changing with the concentration of $\mathrm{Hg}^{2+}$. (b) The absorption spectra of mixed solutions of different concentrations of mercury nitrate and NCDs.

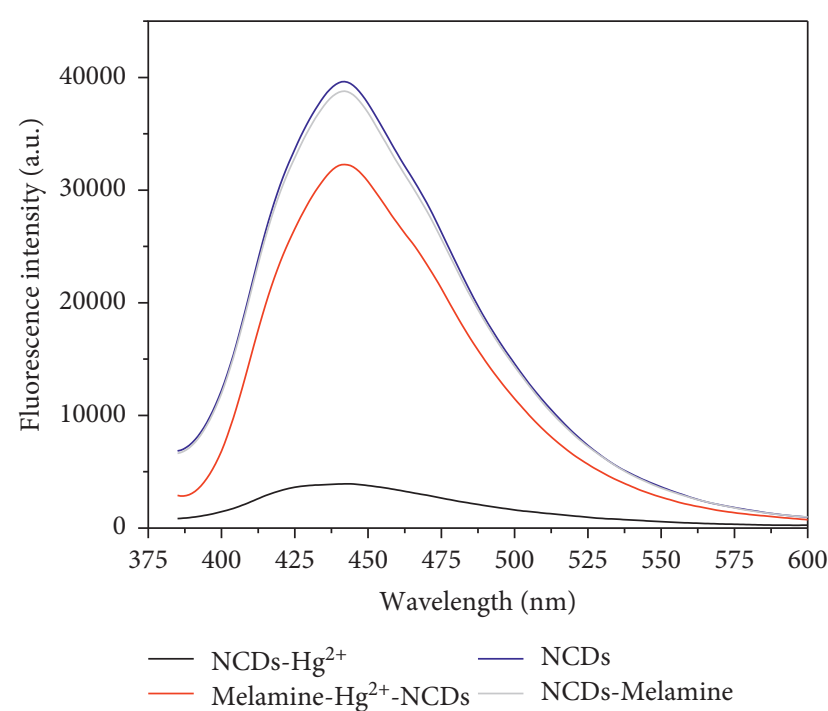

Figure 3: The fluorescence emission spectra of NCDs (blue line), NCDs-melamine mixed solution (gray line), melamine- $\mathrm{Hg}^{2+}$ NCDs mixed solution (red line), and NCDs- $\mathrm{Hg}^{2+}$ mixed solution (black line) $\left(\lambda_{\mathrm{ex}}=370 \mathrm{~nm}, \mathrm{NCD}\right.$ were diluted five times, $\mathrm{Hg}^{2+}=1.2 \mathrm{mM}$, melamine $\left.=3 \mathrm{mg} / \mathrm{L}\right)$.

experimental conditions are melamine $=0-10 \mathrm{mg} / \mathrm{L}$, $\mathrm{Hg}^{2+}=6 \mathrm{mM}$, and NCDs (black line); melamine $=0-10 \mathrm{mg}$ / $\mathrm{L}, \mathrm{Hg}^{2+}=1.2 \mathrm{mM}$, and NCDs are diluted five times (red line); melamine $=0-10 \mathrm{mg} / \mathrm{L}, \mathrm{Hg}^{2+}=0.6 \mathrm{mM}$, and NCDs are diluted ten times (blue line); and melamine $=0-10 \mathrm{mg} / \mathrm{L}$, $\mathrm{Hg}^{2+}=0.4 \mathrm{mM}$, and NCDs are diluted fifteen times (gray line).

Due to the combination of $\mathrm{Hg}^{2+}$ and melamine, the fluorescence intensity of the system increases with the increase of melamine concentration. However, $\mathrm{Hg}^{2+}$ is not completely bound by melamine when the concentration of
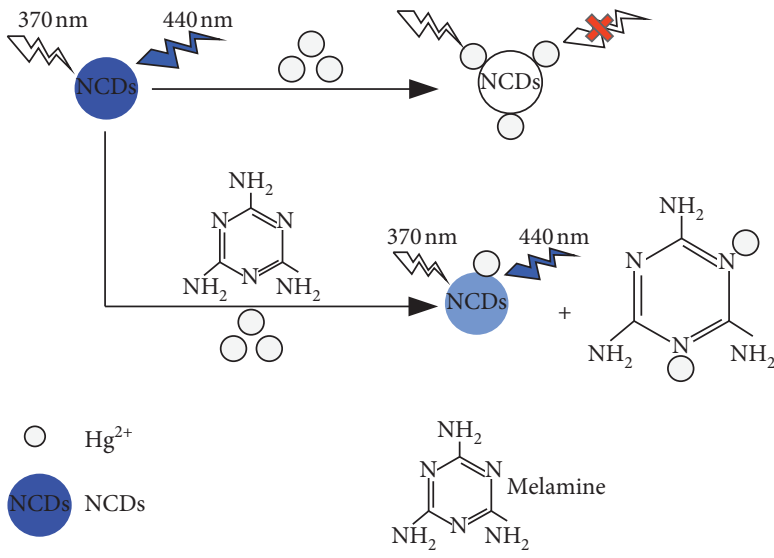

Scheme 1: The process of the melamine- $\mathrm{Hg}^{2+}-\mathrm{NCD}$ system.

melamine is $0-10 \mathrm{mg} / \mathrm{L}$ due to the high concentration of $\mathrm{Hg}^{2+}$ shown as the black line. There is a low sensitivity under this condition. As shown as the red line, the decrease of $\mathrm{Hg}^{2+}$ concentration makes it to only need a small amount of melamine to cooperate with it. When the melamine concentration is $0-4 \mathrm{mg} / \mathrm{L}$, the fluorescence intensity of the system gradually increases and the sensitivity is higher when the melamine concentration increases. The fluorescence intensity of the system has become flat when the concentration is $4-10 \mathrm{mg} / \mathrm{L}$. This condition is used in this article. As shown as the blue line and the gray line, the low concentration of melamine $(0-1 \mathrm{mg} / \mathrm{L})$ is detected with better sensitivity when the concentration of $\mathrm{Hg}^{2+}$ is lowered again. But, when the concentration of melamine is high $(1-4 \mathrm{mg} / \mathrm{L})$, the detection sensitivity is reduced because the amount of NCDs are also small at this time and the fluorescence intensity is weak. Therefore, in 


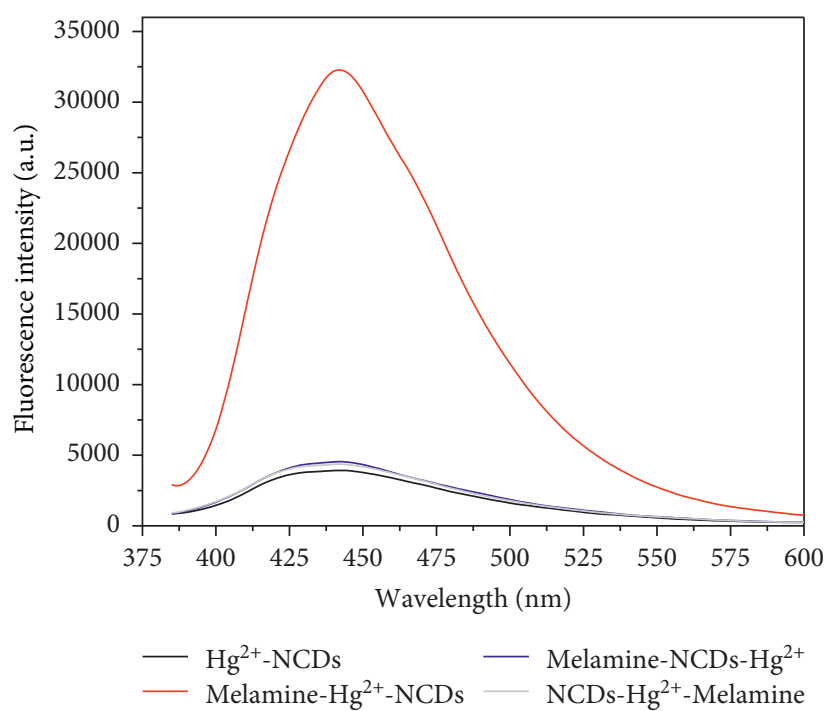

Figure 4: The fluorescence emission spectra of NCDs- $\mathrm{Hg}^{2+}$ mixed solution (black line), melamine- $\mathrm{Hg}^{2+}-\mathrm{NCD}$ mixed solution (red line), melamine-NCDs- $\mathrm{Hg}^{2+}$ mixed solution (blue line), and NCDs- $\mathrm{Hg}^{2+}$-melamine mixed solution (gray line) $\left(\lambda_{\text {ex }}=370 \mathrm{~nm}\right.$, NCDs were diluted five times, $\mathrm{Hg}^{2+}=1.2 \mathrm{mM}$, melamine $=3 \mathrm{mg} / \mathrm{L}$ ).

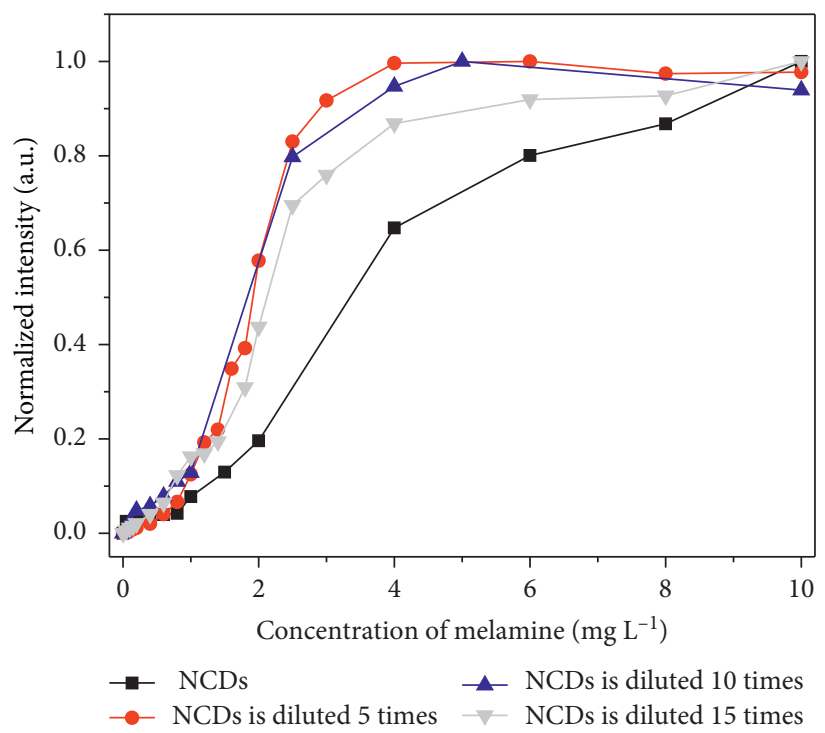

Figure 5: Comparison of the fluorescence peak intensity (normalized) of the system when different concentrations of $\mathrm{Hg}^{2+}$ were mixed with melamine and then added with different concentrations of NCDs.

order to detect the high sensitivity of melamine, NCDs (diluted 5 times) and $\mathrm{Hg}^{2+}(1.2 \mathrm{mM})$ are selected as experimental conditions.

3.6. The Determination of Melamine Concentration. The concentration of melamine was detected by using the melamine- $\mathrm{Hg}^{2+}-\mathrm{NCD}$ system. The fluorescence emission spectrum of the system is shown in Figure 6 $\left(\lambda_{\text {ex }}=370 \mathrm{~nm}\right.$, NCDs were diluted 5 times, $\mathrm{Hg}^{2+}=1.2 \mathrm{mM}$, melamine $=0-10 \mathrm{mg} / \mathrm{L})$. As evident from the figure, the fluorescence intensity of the system gradually increases as the increase of the melamine concentration.
The inset in Figure 6(a) was the graph of the fluorescence peak intensity of the system. The fluorescence intensity of the system increases with the increase of melamine degree. It has a higher sensitivity when the concentration of melamine is $0-3 \mathrm{mg} / \mathrm{L}$. The increasing trend of the fluorescence intensity of the system tends to be flat when the melamine concentration is $3-4 \mathrm{mg} / \mathrm{L}$. Then, the fluorescence intensity of the system has not significantly changed when the melamine concentration is $4-10 \mathrm{mg} / \mathrm{L}$. It indicates that the $\mathrm{Hg}^{2+}$ in the solution had been completely bound by melamine at this time.

It can be seen from Figures 6(b) and 6(c) that NCDs, as a fluorescent probe, have good detection performance for 


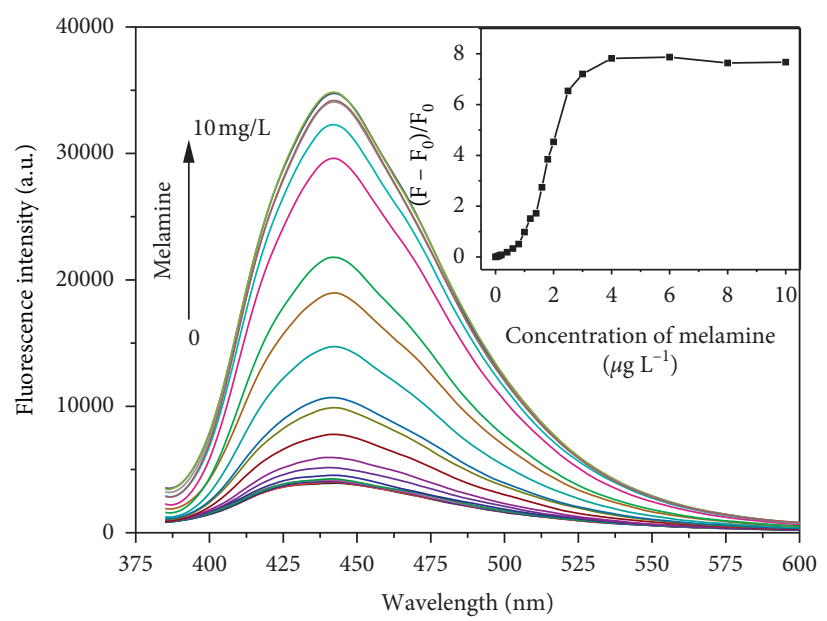

(a)

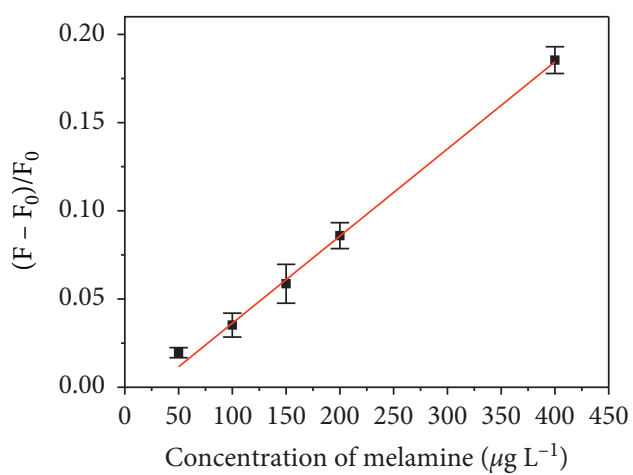

(b)

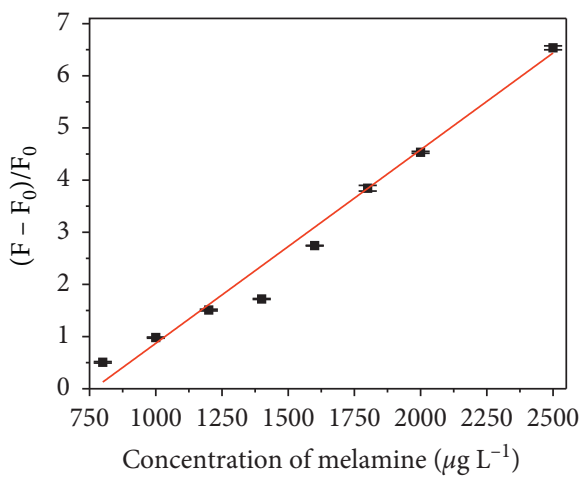

(c)

Figure 6: (a) The fluorescence emission spectrum of the system $\left(\lambda_{\text {ex }}=370 \mathrm{~nm}\right.$, NCDs were diluted 5 times, $\mathrm{Hg}^{2+}=1.2 \mathrm{mM}$, melamine $=0-10 \mathrm{mg} / \mathrm{L}$ ). Inset of (a) show the graph of the peak intensity of the system. (b) A linear relationship of $\left(\mathrm{F}-\mathrm{F}_{0}\right) / \mathrm{F}_{0}$ versus the concentration of melamine over the range $50-400 \mu \mathrm{g} / \mathrm{L}$. (c) A linear relationship of $\left(\mathrm{F}-\mathrm{F}_{0}\right) / \mathrm{F}_{0}$ versus the concentration of melamine over the range $800-2500 \mu \mathrm{g} / \mathrm{L}\left(\mathrm{F}_{0}\right.$ and $\mathrm{F}$ are the fluorescence intensities of the system at $440 \mathrm{~nm}$ in the absence and presence of melamine, respectively).

measuring melamine concentration. When the melamine concentration is $0-2500 \mu \mathrm{g} / \mathrm{L}$, there are two linear ranges. The linear ranges are $50-400 \mu \mathrm{g} / \mathrm{L}$ and $800-2500 \mu \mathrm{g} / \mathrm{L}$, the correlation coefficients $\left(R^{2}\right)$ are 0.997 and 0.988 respectively, and the LOD is $21.76 \mu \mathrm{g} / \mathrm{L}$. The error bars are calculated by three separate sets of melamine solution.

To verify the selectivity of the melamine- $\mathrm{Hg}^{2+}$-NCDs system, we investigate the fluorescence response of the system in the presence of different interfering substances. We have selected several common amino group containing molecules which includes urea, biuret, tryptophan (Trp), phenylalanine (Phe), tyrosine (Tyr), valine (Val), alanine (Ala), and glycine (Gly). The effect of amino group-containing molecules on the system is shown in Figure 7.

For the convenience of comparison, we set the same concentration of these samples to $0.4 \mathrm{mM}$. The black bars show the fluorescence peak intensity (normalized) of these samples mixed with NCDs. It can be seen that there is no obvious difference in the fluorescence intensity of these samples mixed with NCDs, which means that these samples have no significant influence on the NCDs. The blue bars are the fluorescence peak intensities of $\mathrm{Hg}^{2+}$ mixed with NCDs.
The fluorescence of NCDs can be quenched by $\mathrm{Hg}^{2+}$. Since melamine can be combined with $\mathrm{Hg}^{2+}$, the fluorescence of NCDs is only quenched by a small part of the $\mathrm{Hg}^{2+}$ at the first of red bar. The fluorescence intensity of the system is relatively high. Then, these amino group-containing molecules samples replace the melamine in the melamine- $\mathrm{Hg}^{2+}$-NCDs system. The results are shown in the other red bars. The fluorescence intensity of other samples is close to the blue bars. It suggests that these amino-containing samples will not have a significant impact on the system. It is also proved that the mechanism of the system is the combination of the triazine nitrogen-containing heterocycle of melamine and $\mathrm{Hg}^{2+}$.

In order to prove the repeatability and quasidetermination of this method, the standard addition experiment was carried out. Table 1 provides the recoveries and RSD of melamine spiked and measured in deionized water. It can be seen that recoveries of melamine for these samples are calculated in the range of $92.92-106.01 \%$ with satisfactory consequence. The relative standard deviation (RSD) is calculated by repeating the experiment 5 times under the same conditions and is in the range of $1.77-4.5 \%$, indicating a 


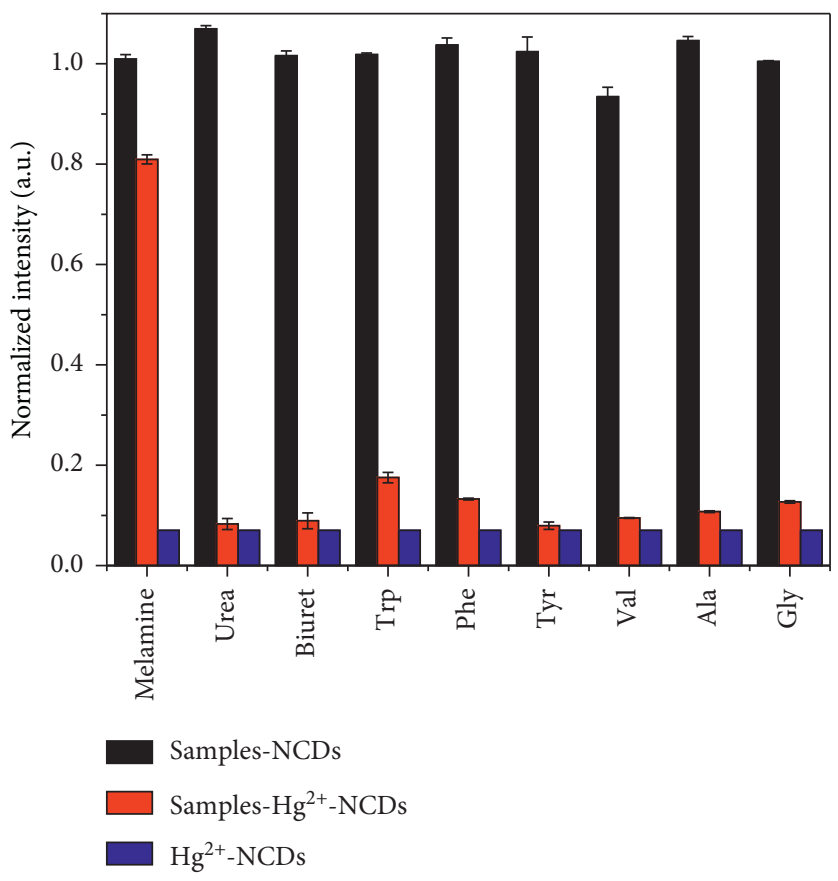

Figure 7: The interference experiment of amino group-containing molecules on the system, including urea, biuret, Trp, Phe, Tyr, Val, Ala, and Gly. The concentration of all samples was $0.4 \mathrm{mM}$.

TABle 1: Analysis of deionized water spiked with different amounts of melamine $(n=5)$.

\begin{tabular}{lcccc}
\hline \multirow{2}{*}{ Sample } & \multicolumn{2}{c}{ Concentration of melamine $(\mu \mathrm{g} / \mathrm{L})$} & Recovery $(\%)$ & RSD $(\%)$ \\
& Spiked & Measured & 106.01 & 4.5 \\
1 & 250 & 265.02 & 92.92 & 2.14 \\
3 & 1250 & 1161.52 & 99.36 & 1.77 \\
\hline
\end{tabular}

TABLE 2: Comparison of linear range, LOD, and detection time of different fluorescent probes for melamine detection.

\begin{tabular}{|c|c|c|c|c|}
\hline Fluorescent probe & Linear range & LOD & $\begin{array}{c}\text { Detection } \\
\text { time (min) }\end{array}$ & Ref. \\
\hline FRET between CDs and Au NPs & $50-500 \mathrm{nM}$ & $36 \mathrm{nM}$ & 35 & {$[27]$} \\
\hline $\mathrm{CDs}-\mathrm{Hg}^{2+}$ & $1-20 \mu \mathrm{M}$ & $0.3 \mu \mathrm{M}$ & 13 & [29] \\
\hline NCDs-Fe ${ }^{3+}$ & $2-290 \mu \mathrm{M}$ & $0.66 \mu \mathrm{M}$ & 30 & {$[34]$} \\
\hline Aptamer-modified Au NPs & $1.2-2.4 \mu \mathrm{M}$ and $2.4-20.62 \mu \mathrm{M}$ & $793 \mathrm{nM}$ & 30 & {$[35]$} \\
\hline $\mathrm{NCDs}-\mathrm{Hg}^{2+}$ & $\begin{array}{c}50-400 \mu \mathrm{g} / \mathrm{L}(0.4-3.17 \mu \mathrm{M}) \text { and } 800-2500 \mu \mathrm{g} / \mathrm{L} \\
(6.34-19.8 \mu \mathrm{M})\end{array}$ & $21.76 \mu \mathrm{g} / \mathrm{L}(0.17 \mu \mathrm{M})$ & 10 & This work \\
\hline
\end{tabular}

good reproducibility of this system. The results show that the melamine- $\mathrm{Hg}^{2+}-\mathrm{NCD}$ system is reliable in detecting melamine concentration.

In addition, this study is compared with other melamine detection methods. Table 2 provides the linear range, LOD, and detection time of different fluorescent probes for melamine detection in the literature [27, 29, 34, 35].

\section{Conclusions}

In summary, a method for detecting the concentration of melamine based on changes in the fluorescence intensity of
NCDs was explored. By using the mechanism of quench and interaction inside the melamine- $\mathrm{Hg}^{2+}-\mathrm{NCD}$ system, the detection method was established. Then, the relationship between the concentration of melamine and the fluorescence intensity of the system was obtained. The results showed that the manufacturing process of NCDs is straightforward, the detection is convenient and quick, and it has high sensitivity and large measurement range. The two linear ranges are $50-400 \mu \mathrm{g} / \mathrm{L}$ and $800-2500 \mu \mathrm{g} / \mathrm{L}$, the LOD is $21.76 \mu \mathrm{g} / \mathrm{L}$, and $R^{2}$ is 0.997 and 0.988 , respectively. The sensitive detection of melamine is revealed, and the research work can bring new sight for food safety detection. 


\section{Data Availability}

The data used to support the findings of this study are available from the corresponding author upon request.

\section{Conflicts of Interest}

The authors declare that they have no conflicts of interest.

\section{Acknowledgments}

The authors greatly appreciate the National Key R\&D Project (2018YFC1604204-3), National Food Science and Engineering First-Class Discipline Construction Project (JUFSTR20180302), National Natural Science Foundation of China (61378037), and the Key Research and Development Program of Jiangsu Province (BE2020756) for financial support.

\section{References}

[1] Q. Wu, Q. Long, H. Li, Y. Zhang, and S. Yao, "An upconversion fluorescence resonance energy transfer nanosensor for one step detection of melamine in raw milk," Talanta, vol. 136, pp. 47-53, 2015.

[2] Y. Li, J. Xu, and C. Sun, "Chemical sensors and biosensors for the detection of melamine," RSC Advances, vol. 5, no. 2, pp. 1125-1147, 2015.

[3] T. Wu, H. Chen, Z. Lin, and C. Tan, "Identification and quantitation of melamine in milk by near-infrared spectroscopy and chemometrics," Journal of Spectroscopy, vol. 2016, no. 2, pp. 1-8, 2016.

[4] J. Y. W. Chan, C. M. Lau, T. L. Ting et al., "Gestational and lactational transfer of melamine following gavage administration of a single dose to rats," Food and Chemical Toxicology, vol. 49, no. 7, pp. 1544-1548, 2011.

[5] L. Zhu, G. Xu, F. Wei, J. Yang, and Q. Hu, "Determination of melamine in powdered milk by molecularly imprinted stir bar sorptive extraction coupled with HPLC," Journal of Colloid and Interface Science, vol. 454, pp. 8-13, 2015.

[6] F. X. Sun, W. Ma, L. G. Xu et al., "Analytical methods and recent developments in the detection of melamine," TrAC: Trends in Analytical Chemistry, vol. 29, no. 11, pp. 1239121249, 2010

[7] T. Wang, J. Ma, Y. Chen, Y. Li, L. Zhang, and Y. Zhang, "Analysis of melamine and analogs in complex matrices: advances and trends," Journal of Separation Science, vol. 40, no. 1, pp. 170-182, 2017.

[8] X. Yang, Z. Jia, Z. Tan, H. Xu, N. Luo, and X. Liao, “Determination of melamine in infant formulas by fluorescence quenching based on the functionalized Au nanoclusters," Food Control, vol. 70, pp. 286-292, 2016.

[9] J. Liu, Y. Zhong, J. Liu, H. Zhang, J. Xi, and J. Wang, “An enzyme linked immunosorbent assay for the determination of cyromazine and melamine residues in animal muscle tissues," Food Control, vol. 21, no. 11, pp. 1482-1487, 2010.

[10] H. Lei, R. Su, S. A. Haughey et al., "Development of a specifically enhanced enzyme-linked immunosorbent assay for the detection of melamine in milk," Molecules, vol. 16, no. 7, pp. 5591-5603, 2011.

[11] N. Yang, L. L. Xie, C. Pan et al., "A novel on-chip solution enabling rapid analysis of melamine and chloramphenicol in milk by smartphones," Journal of Food Process Engineering, vol. 42, no. 2, Article ID e12976, 2019.

[12] G. Venkatasami and J. R. Sowa, "A rapid, acetonitrile-free, HPLC method for determination of melamine in infant formula," Analytica Chimica Acta, vol. 665, no. 2, pp. 227-230, 2010.

[13] M. Lin, L. He, J. Awila et al., "Detection of melamine in gluten, chicken feed, and processed foods using surface enhanced Raman spectroscopy and HPLC," Journal of Food Science, vol. 73, no. 8, pp. T129-T134, 2010.

[14] A. Khedr, "Optimized extraction method for LC-MS determination of bisphenol a, melamine and di (2-ethylhexyl) phthalate in selected soft drinks, syringes, and milk powder," Journal of Chromatography B, vol. 930, no. 6, pp. 98-103, 2013.

[15] J. Ge, L. W. Zhao, C. Liu, S. Jiang, P. W. Lee, and F. Liu, "Rapid determination of melamine in soil and strawberry by liquid chromatography-tandem mass spectrometry," Food Control, vol. 22, no. 10, pp. 1629-1633, 2011.

[16] X.-D. Pan, P.-G. Wu, D.-J. Yang, L.-Y. Wang, X.-H. Shen, and C.-Y. Zhu, "Simultaneous determination of melamine and cyanuric acid in dairy products by mixed-mode solid phase extraction and GC-MS," Food Control, vol. 30, no. 2, pp. 545-548, 2013.

[17] H. Miao, S. Fan, Y.-N. Wu et al., "Simultaneous determination of melamine, ammelide, ammeline, and cyanuric acid in milk and milk products by Gas Chromatography-tandem Mass Spectrometry," Biomedical and Environmental Sciences, vol. 22, no. 2, pp. 87-94, 2009.

[18] S. K. Kailasa and H.-F. Wu, "Electrospray ionization tandem mass spectrometry for rapid, sensitive and direct detection of melamine in dairy products," Journal of Industrial and Engineering Chemistry, vol. 21, pp. 138-144, 2015.

[19] Z. Yang, L. Han, C. Wang et al., "Detection of melamine in soybean meal using near-infrared microscopy imaging with pure component spectra as the evaluation criteria," Journal of Spectroscopy, vol. 201611 pages, 2016.

[20] X. Cao, F. Shen, M. Zhang et al., "Efficient inner filter effect of gold nanoparticles on the fluorescence of CdS quantum dots for sensitive detection of melamine in raw milk," Food Control, vol. 34, no. 1, pp. 221-229, 2013.

[21] H. Dai, Y. Shi, Y. Wang et al., "Label-free turn-on fluorescent detection of melamine based on the anti-quenching ability of $\mathrm{Hg} 2+$ to gold nanoclusters," Biosensors and Bioelectronics, vol. 53, pp. 76-81, 2014.

[22] M. Zhang, X. Cao, H. Li et al., "Sensitive fluorescent detection of melamine in raw milk based on the inner filter effect of $\mathrm{Au}$ nanoparticles on the fluorescence of CdTe quantum dots," Food Chemistry, vol. 135, no. 3, pp. 1894-1900, 2012.

[23] J. Zhao, H. Wu, J. Jiang, and S. Zhao, "Label-free fluorescence turn-on sensing for melamine based on fluorescence resonance energy transfer between CdTe/CdS quantum dots and gold nanoparticles," RSC Advances, vol. 4, no. 106, pp. 61667-61672, 2014.

[24] K. Ai, Y. Liu, and L. Lu, "Hydrogen-bonding recognition-induced color change of gold nanoparticles for visual detection of melamine in raw milk and infant formula," Journal of the American Chemical Society, vol. 131, no. 27, pp. 9496-9497, 2009.

[25] S. K. Kailasa, S. Ha, S. H. Baek et al., "Tuning of carbon dots emission color for sensing of Fe3+ ion and bioimaging applications," Materials Science and Engineering: C, vol. 98, pp. 834-842, 2019.

[26] M. L. Desai, S. Jha, H. Basu, R. K. Singhal, T.-J. Park, and S. K. Kailasa, "Acid oxidation of muskmelon fruit for the 
fabrication of carbon dots with specific emission colors for recognition of $\mathrm{Hg} 2+$ ions and cell imaging," ACS Omega, vol. 4, no. 21, pp. 19332-19340, 2019.

[27] H. Dai, Y. Shi, Y. Wang et al., "A carbon dot based biosensor for melamine detection by fluorescence resonance energy transfer," Sensors and Actuators B: Chemical, vol. 202, no. 10, pp. 201-208, 2014

[28] W.-F. Wang, Y. Qiang, X.-H. Meng, J.-L. Yang, and Y.-P. Shi, "Ultrasensitive colorimetric assay melamine based on in situ reduction to formation of CQDs-silver nanocomposite," Sensors and Actuators B: Chemical, vol. 260, pp. 808-815, 2018.

[29] C. H. Lei, X. E. Zhao, S. L. Jiao et al., "A turn-on fluorescent sensor for the detection of melamine based on the antiquenching ability of $\mathrm{Hg} 2+$ to carbon nanodots," Analytical Methods, vol. 8, no. 22, pp. 4438-4444, 2016.

[30] G. Ren, Q. Zhang, S. Li et al., "One pot synthesis of highly fluorescent $\mathrm{N}$ doped $\mathrm{C}$-dots and used as fluorescent probe detection for $\mathrm{Hg} 2+$ and $\mathrm{Ag}+$ in aqueous solution," Sensors and Actuators B: Chemical, vol. 243, no. 5, pp. 244-253, 2017.

[31] Y. Zhang, P. Cui, F. Zhang et al., "Fluorescent probes for "offon" highly sensitive detection of $\mathrm{Hg} 2+$ and L-cysteine based on nitrogen-doped carbon dots," Talanta, vol. 152, pp. 288$300,2016$.

[32] J. Jian and W. Chen, "Synthesis of highly fluorescent nitrogendoped graphene quantum dots for sensitive, label-free detection of $\mathrm{Fe}$ (III) in aqueous media," Biosensors \& Bioelectronics, vol. 58, pp. 219-225, 2014.

[33] J. Du, S. Yin, L. Jiang, B. Ma, and X. Chen, “A colorimetric logic gate based on free gold nanoparticles and the coordination strategy between melamine and mercury ions," Chemical Communications, vol. 49, no. 39, pp. 4196-4198, 2013.

[34] Q. Zhuang, L. Li, Y. Ding, H. Zeng, and Y. Wu, "Highly luminescent nitrogen-doped carbon dots as "Turn-On" fluorescence probe for selective detection of melamine," Chemistry Select, vol. 4, no. 1, pp. 84-89, 2019.

[35] W. Yun, H. Li, S. Chen, D. Tu, W. Xie, and Y. Huang, "Aptamer-based rapid visual biosensing of melamine in whole milk," European Food Research and Technology, vol. 238, no. 6, pp. 989-995, 2014. 